\title{
Tympanostomy Tube Selection: A Review of the Evidence
}

\author{
${ }^{1}$ Sandra Ho, ${ }^{2}$ David J Kay
}

\begin{abstract}
Tympanostomy tube (TT) insertion for ventilation of the middle ear is one of most commonly performed procedures in the United States. Indications for tube insertion include otitis media with effusion, recurrent acute otitis media, hearing loss caused by middle ear effusion and persistent acute otitis media. In general, TTs are divided into two categories, short-term tubes and long-term tubes. Depending on the indications for tube placement and surgeon experience with the TT, different tubes can be used. A myriad of tubes have been created since their first documented use in 1845 in attempts to provide better middle ear ventilation, improve ease of placement and prevent complications, such as post-tube otorrhea, persistent perforation and tube occlusion. In order for a tube to be effective, it should be biocompatible with the middle ear to minimize a foreign body reaction. Teflon and silicone remain two of the most commonly used materials in TTs. In addition, the tube design also plays a role for insertion and retention times of TTs. Lastly, TTs can also be coated with various substances, such as silver-oxide, phosphorylcholine and more recently, antibiotics and albumin, in order to prevent biofilm formation and decrease the rate of post-TT otorrhea. Persistent middle ear effusion affects many children each year and can impact their quality of life as well as hearing and language development. With nearly 1 out of every 15 children by the age of 3 years receiving TTs, it is imperative that the right tube be chosen to facilitate optimal ventilation of the middle ear while minimizing complications.
\end{abstract}

Keywords: Biofilm, Extrusion, Long-term tubes, Otorrhea, Perforation, Retention, Short-term tubes, Silicone, Tympanostomy tube.

How to cite this article: Ho S, Kay DJ. Tympanostomy Tube Selection: A Review of the Evidence. Int J Head Neck Surg 2016;7(1):17-22.

\section{Source of support: Nil}

Conflict of interest: None

\section{INTRODUCTION}

Tympanostomy tube (TT) insertion for ventilation of the middle ear is the main reason a child receives general anesthesia in the United States, ${ }^{1}$ and is second only to

\footnotetext{
${ }^{1}$ Resident, ${ }^{2}$ Volunteer Professor

${ }^{1}$ Department of Otolaryngology Head and Neck Surgery, SUNY Downstate Medical Center, Brooklyn, New York, USA

${ }^{2}$ Center for Pediatric ENT and Head and Neck Surgery, Florida Atlantic University Charles E. Schmitt College of Medicine, Boynton Beach, Florida, USA

Corresponding Author: Sandra Ho, Resident, Department of Otolaryngology Head and Neck Surgery, 450 Clarkson Avenue Box 126 Brooklyn, New York, USA, Phone: 718-270-1638 e-mail: sandra.ho@downstate.edu
}

neonatal circumcision in being the most common surgical procedure in childhood. ${ }^{2}$ In the United States in 2006 alone, 667,000 children younger than 15 years received TTs. ${ }^{3}$ By the age of 3 years, nearly 1 of every 15 children $(6.8 \%)$ will have TTs, with those attending day care having a 2-fold increase in tube placement. ${ }^{4}$ These numbers are not surprising, given that otitis media (middle ear inflammation) is the second most diagnosed illness in children. ${ }^{5}$

\section{HISTORY}

One of the first documented use of TTs occurred in 1845, when two men, Martell Frank of Munich and Gustav Lincke of Leipzig, used a tube of gold with a small projection at each end to keep a perforation open. ${ }^{6}$ Then in 1860, a French military surgeon, Jean-Pierre Bonnafont created a silver cannula as long as the external auditory canal and as large as the artificial aperture of the tympanic membrane (TM). The cannula also had 'two small ailerons mounted on two stems' that essentially acted as flanges. ${ }^{7}$ He then went on to create a smaller cannula, termed an 'eyelet' with an attached piece of waxed silk so that the tube could be removed easily. ${ }^{8}$ Creation of TTs continued with the work of Adam Politzer in 1868, who developed a hard rubber drain that was used to keep the myringotomy incision open. ${ }^{9}$ The success of these tubes for treating chronic middle ear fluid were limited, however, due to pain, plugging, early extrusion and infection, ${ }^{10}$ and was largely abandoned in favor of adenoidectomy.

It was not until 1954 when TTs regained popularity after Armstrong published a successful series of five patients with polyethylene tube insertion. ${ }^{11}$ Over the following half-century, tubes have evolved to encompass a myriad of design styles and construction materials. In deciding what particular type of tube to place, there are two primary variables to consider: The material from which the tube is constructed, and the design or shape that material is constructed into.

\section{TUBE MATERIALS}

Tympanostomy tube are manufactured from a variety of materials, most commonly from plastics or metals. To be effective as a TT, the substance must be biocompatible with the middle ear. ${ }^{12}$ Because the tube will initiate a foreign body reaction by the host patient, minimizing 
this reaction will maximize the tubes' retention times. Because of their relative inertness, many metals, such as stainless steel, gold and titanium, have been used to manufacture TTs.

One of the most common materials used for TTs is fluoroplastic. Originally developed under the brand name Teflon, polytetrafluoroethylene (PTFE) consists of fluorine atoms covalently bound to carbon atoms. ${ }^{13}$ Another commonly used material is silicone. It is soft and flexible, facilitating removal in the office.

\section{TUBE DESIGN}

Many different types of tube designs exist, but most tubes can be categorized into either short-term or long-term tubes. Structurally, their primary difference is the presence or absence of an outer flange, with the absence of an outer flange in long-term tubes. Functionally, short-term tubes are intended to remain in the TM for approximately 8 to 18 months, and long-term tubes have retention times from 15 months to years. ${ }^{12,14}$ The presence of the outer flange is what dictates the length of retention time between the tubes. After the tube is inserted, the TM starts to heal. As the squamous layer of the TM keratinizes, it starts pushing the tube posterior-inferiorly. ${ }^{15}$ In shortterm tubes, the keratin builds up behind the outer flange, and gradually pushes the tube out. As long-term tubes do not have an outer flange, the keratin is unable to build up behind the flange resulting in longer tube retention times.

\section{CHOOSING THE TYPE OF TUBE TO INSERT}

\section{Biocompatibility}

In order to minimize complications and ensure continued effectiveness of the tube, the tube has to be biocompatible with the middle ear. ${ }^{12}$ Inert substances, like metals, particularly stainless steel, are ideal substances to use because they minimize tissue rejection. Gold is another example of a metal that has been used to create TTs. ${ }^{16}$

Other substances, such as fluoroplastic (Teflon, PTFE) are also used to create TTs. Their high heat resistance along with their chemical inertness helps to prevent rejection. Silicone, which consists of alternating silicone and oxygen atoms creates a flexible polymer that is stable over a wide temperature range. ${ }^{13}$ With increasing biocompatibility, the goal is to create less of a host tissue reaction with a subsequent decrease in the incidence of potential complications, including infection. A randomized trial of 31 children receiving titanium tubes in one ear and Shepard fluoroplastic tubes in another demonstrated more granulation tissue around the titanium tubes and an increased rate of infection. ${ }^{17}$ Another study of 10 rats undergoing myringotomy and tube placement found that structural changes in the TM were most pronounced with plain polyethylene tubes, than with stainless steel tubes and lastly with fluoroplastic tubes. ${ }^{18}$ In clinical studies, where histological analysis of the TM is difficult, an indirect method of assessing biocompatibility is evidence of tympanosclerosis. In a systematic literature review of tube sequelae in 41 studies looking at 7,197 ears, the investigators found no differences in the rates of tympanosclerosis between short-term tubes and long-term tubes. ${ }^{14}$

\section{Surface Composition}

In many instances, the cause of tube blockage and infection is the development of a biofilm. In efforts to further biocompatibility and reduce the incidence of these complications, TTs have been coated with various substances. Silicone tubes have been impregnated with silver oxide and high-energy argon atoms in efforts to reduce tube otorrhea. The argon atoms smooth the surface of the silicone and decreases the tube's adhesiveness. Teflon tubes can be coated with phosphorylcholine (PC), which attracts water molecules and thereby repels other molecules. Other strategies include antibiotic coated tubes ${ }^{19,20}$ and albumin coated tubes. ${ }^{21-23}$

An in vitro study used scanning electron microscopy to compare PC-coated fluoroplastic TTs to plain fluoroplastic and silver oxide-impregnated fluoroplastic tubes for resistance to biofilm formation after in vitro incubation with Staphylococcus aureus or Pseudomonas aeruginosa. This study found biofilm formation from Pseudomonas on the untreated fluoroplastic tubes and both $S$. aureus and $P$. aeruginosa on the silver oxide-impregnated tubes. The PC coated fluoroplastic tube however, showed resistance to both bacterial biofilm formation. ${ }^{24} \mathrm{~A}$ more recent in vitro study in 2013 by Ojano-Dirain et al looking at polyvinylpyrrolidone (PVP) and/or silver-oxide coated tubes found that PVP, silver and PVP-silver coatings reduced P. aeruginosa biofilm formation relative to silicone, but that PVP and PVP-silver coatings increased S. aureus biofilm formation. ${ }^{25}$ In contrast, Patel et al found no statistically significant difference in an in vitro model between human serum albumin coated titanium, PC-coated fluoroplastic and PVP-coated silicone TTs and uncoated tubes in the development of tube occlusion. ${ }^{26}$

Up until recently, there was a paucity of literature on coated tube biofilm formation and postoperative complications in human subjects. In 2006, Tatar et al performed a prospective cohort study in 30 patients looking at untreated silastic TTs and 16 ionized, processed TTs and found that ionized processed silastic TTs had a statistically significant decreased rate of biofilm formation, plugging and otorrhea compared with untreated TTs. ${ }^{27}$ 
In 2008, Licameli et al performed a prospective cohort study on 70 children, randomizing them to receive a PC TT in one ear and an uncoated tube in the other and analyzed the incidence of TT complications, such as otorrhea, premature extrusion, persistent TM perforations, granulation tissue and tube lumen obstruction. ${ }^{28}$ They did not find a statistically significant difference in any of the outcomes between the non-coated and coated tubes. A more recent prospective randomized clinical trial by Hong et al in 2011 looking at PC-coated tubes vs noncoated TTs in 240 children also found no differences in development of tube otorrhea, tube lumen blockage and early extrusion. $^{29}$

Other strategies, such as antibiotic coated TTs have also been used in attempts to lower the incidence of biofilm formation. An in vitro study by Jang et al in 2009 comparing piperacillin-tazobactam coated silicone tubes, silver-oxide coated silicone tubes and uncoated TTs to the development of ciprofloxacin-resistant P. aeruginosa (CRPA) biofilms found the piperacillin-tazobactam coated TTs had virtually no CRPA biofilm formation in contrast to the silver-oxide coated and uncoated tubes that developed a thick biofilm with crusts. ${ }^{19}$ Jang et al performed a similar study in 2010 looking at vancomycin-coated silicone tubes for development of methicillin-resistant S. aureus (MRSA) biofilms and found the same results. ${ }^{20}$

Biofilm formation on albumin coated TTs have also been investigated. Kinnari et al initially experimented with albumin coated silicone tubes. Fibronectin, a typical adhesive protein in serum and exudates was used as the model to represent exudates of the ear. Binding inhibition of fibronectin was measured during an 8-month trial. They found that albumin coating markedly inhibits the binding of fibronectin on tube surfaces in vitro. ${ }^{21}$ The authors then performed a randomized double-blinded clinical trial looking at albumin coated tubes in 2007 and found that there was a 50\% lower incidence of early tube occlusion in patients with albumin-coated tubes. There was no difference in tube otorrhea between the coated and non-coated tubes. ${ }^{22}$ They then performed a follow-up study looking at the ventilation time and development of otorrhea of coated vs non-coated tubes over a period of 9 months and again found no difference between coated vs non-coated tubes. ${ }^{23}$

\section{COMPLICATIONS/POST-TYMPANOSTOMY TUBE INSERTION}

\section{Tube Otorrhea}

Tube otorrhea is a complication that can occur after placement of TTs. It can manifest as an early or late complication. Early onset usually occurs within 2 weeks of tube placement and has been reported to occur in 10 to $20 \%$ of children. Late onset occurs greater than 2 weeks after tube placement and has reported to occur in 30\% of children, with $7 \%$ developing recurrent otorrhea. ${ }^{30}$ It is thought that biofilm formation contributes to the development of tube otorrhea. As mentioned above, different tube and surface compositions can affect the development of biofilms. Silver oxide impregnated fluoroplastic and silicone tubes have been created in efforts to reduce tube otorrhea. ${ }^{31}$ In 1995, a randomized controlled trial of 125 children receiving a Silastic TT in one ear and a silver oxide impregnated TT in the other ear found a long-term decrease in incidence of tube otorrhea in the silver oxide-impregnated TTs. ${ }^{31}$ Another method that has been employed to decrease tube otorrhea is the use of semipermeable membranes within the lumen of the tubes. ${ }^{32,33}$

Multiple other studies have looked at the development of tube otorrhea after the insertion of different types of tubes. In one study by Tami et al, gold-plated TTs were compared with Teflon tubes at monthly follow-up for 12 months. The investigators found no statistically significant difference in the rate of tube otorrhea between the tubes, but that the gold-plated tube had a significantly higher rate of early extrusion compared to the Teflon tube. ${ }^{16}$ A similar study by Karlan et al, demonstrated that compared with silicone tubes, fluoroplastic tubes showed significantly less otorrhea in the early postoperative period. ${ }^{13}$ Another study with 31 children comparing titanium tubes in one ear and fluoroplastic tubes in the other showed a nonsignificant trend toward tube otorrhea with the titanium tubes. ${ }^{17}$

Another study compared the outcomes of four different types of commonly used TTs: Shepard Teflon grommet, Armstrong beveled tube, Reuter-Bobbin tube and the Goode T-Tube. It is the only prospective randomized study comparing the outcomes in more than one tube. Seventy-five children had a T-tube placed in the right ear and the left ear was randomized to one of the other three tubes. They found that the Shepard and Armstrong tubes showed a comparatively low rate of plugging and otorrhea, 0 and $17 \%$, respectively, whereas the T-tube had a $50 \%$ incidence of otorrhea and the Reuter-Bobbin had a $42 \%$ incidence. ${ }^{34}$

\section{Persistent Perforation}

The same study mentioned above comparing the four types of tubes also found that the rates of residual TM perforations occur more commonly with long-term tubes, with residual perforations only being seen in the Goode T-tube group. ${ }^{34}$ A systematic review of the outcomes following TT placement showed a similar finding, with short-term tubes demonstrating a $2.2 \%$ rate of residual perforation compared with $16.6 \%$ in long-term tubes. ${ }^{14}$ 
Kalcioglu et al in 2003 looked at 366 ears after TT insertion and found that the rate of persistent TM perforation was $8.7 \%$ in patients with T-tubes and $4.4 \%$ in patients with Shepard grommet tubes. ${ }^{35}$ Recently, around 2002, a new silicone TT was developed to help address the issues of persistent perforations with T-tubes. The Triune TT tube features three flanges to help keep the tube perpendicular to the eardrum. The three flanges are also angled to contour to the TM. These features were designed to help to prevent unnecessary erosion of the tympanic membrane tissues, which might affect post-tube extrusion healing of the TM and result in persistent perforations. In a study performed looking at complications after Triune TT placement, they found a $1.3 \%$ rate of perforations (2 of 156 ears with extruded tubes). ${ }^{36}$

\section{Extrusion and Retention Times}

The duration a TT remains in the TM depends on a variety of host factors as well as the type of tube itself. Short-term tubes are intended to remain in the TM for approximately 8 to 18 months, and long-term tubes are made to stay in the ear for approximately 15 months to years. ${ }^{12,14}$ As mentioned before, the metals and fluoroplastics have smooth surfaces and allow for decreased mucus adherence. By creating less of a host reaction, the TT will be less likely to extrude.

In one study by Shone and Griffith in 1990, the authors compared extrusion rates of titanium grommets with Teflon grommets and found that after 8 months, there were significantly more titanium grommets still functioning, but that at 12 and 16 months, there was no difference in extrusion rates and that the titanium grommets had more granulation tissue formation around the tube. ${ }^{17}$ A similar study by Handler et al in 100 children comparing titanium tubes with Paparella silicone tubes also found no difference in extrusion rates at 1 year. ${ }^{37}$ In a prospective, randomized study looking at four short-term tubes, Shepard fluoroplastic, Armstrong beveled, Reuter-Bobbin, and Goode T-tubes, there was no difference in extrusion rates among the three shortterm tubes. ${ }^{34}$

Recently, development of a dissolvable TT has been described. Sherman et al in 2010 looked at a dissolvable TT developed from calcium alginate. Calcium alginate gels have a unique feature in that their chemical bonds are reversible, enabling them to be rapidly degraded in the presence of sodium, magnesium, and potassium. In this study, the investigators demonstrated a $20 \%$ reduced occlusion rate compared to traditional silicone tubes in vitro. Their ability to dissolve on their own or with certain ototopical solutions could theoretically be an advantage for patients that are unable to tolerate removal in the office and minimize the need for a procedure in the operating room. It also may provide an advantage in patients that have unreliable follow-up. ${ }^{38}$

\section{OCCLUSION}

Tympanostomy tube occlusion is a relatively common postoperative complication, with a reported incidence of 4.7 to $13.1 \% .{ }^{39}$ When the tube becomes blocked, the clinical utility of the tube becomes obsolete. Studies have been done looking at the influence the lumen diameter and length have on tube occlusion. An ex-vivo study by Burke et al in 2009 compared the efficacy of common solutions to dissolve TTs of differing lengths and diameters. ${ }^{40}$ Two types of tubes, the fluoroplastic collar button tube (CBT), with an inner diameter of $1.27 \mathrm{~mm}$ and shaft length of $1.5 \mathrm{~mm}$ and the Richards T-tube (RTT), with an inner diameter of $1.14 \mathrm{~mm}$ and a shaft length of $12 \mathrm{~mm}$ were used. The tubes were blocked with the investigator's blood. Overall, the investigators found that more RTTs were unblocked compared to CBTs. This was in contrast to a study by Mehta et al that found TTs with larger inner diameters and greater shaft lengths cleared plugs more rapidly, but the results did not reach statistical significance. ${ }^{41}$

A study of 75 children randomized to one of three short-term tubes (Shepard, Armstrong beveled and the Reuter-Bobbin) found that the Reuter-Bobbin had an increased rate of tube obstruction. The Reuter-Bobbin was the narrowest tube however, with an inner diameter of $1.0 \mathrm{~mm}$ compared with the Armstrong and Shepard tubes, which had inner diameters of $1.14 \mathrm{~mm} .{ }^{34}$ Tami et al had 28 children with a fluoroplastic Sheehy collar button tube in one ear and a Microtek gold tube in the other ear. Both tubes had an inner diameter of $1.25 \mathrm{~mm}$. They found no significant difference in tube occlusion rates after 1 year. $^{16}$

A study by Tsao et al in 2003 looked at the effect of tube composition on the opening of plugged TTs. ${ }^{42}$ They examined silicone Paperellas, titanium fluoroplastic, stainless steel Reuter-Bobbins, ion-bombarded silicone Donaldsons and PC-coated fluoroplastic Reuter-Bobbins. Each tube had an internal diameter of $1.14 \mathrm{~mm}$, with shaft lengths of $1 \pm 0.1 \mathrm{~mm}$. They plugged each tube with frozen, pooled human mucoid middle ear effusion and ofloxacin otic solution was used to clear the plug. They found no statistically significant difference between the tube types, but did find a significant difference between silicone and ion-bombarded silicone tubes, with ion-bombarded silicone tubes have higher rates of unplugging.

\section{CONCLUSION}

Since their debut in 1845, a myriad of TTs have been created, each with minute differences in their inherent 
and surface composition and structure. It is amazing to witness the impact such small tubes can have on a child's development of hearing and language. It is therefore imperative that all the available evidence be used in choosing the most appropriate TT. Fluoroplastic tubes, with the low adhesiveness and chemical inertness, have been shown in many studies to be effective while causing low rates of complications. They have also been in use for many years, yielding predictable clinical results. For long-term tubes, silicone has been shown to be superior, offering ease of both tube insertion and removal.

With regards to surface composition of the tube, many studies have now looked at ways to decrease biofilm formation and hence the rates of tube occlusion and infection. While many in vitro and human studies have not shown statistically significant differences in biofilm formation with silver-oxide, PC-coated and albumincoated TTs, there have been statistically significant differences in biofilm formation with antibiotic-coated tubes. More human studies need to be performed in order to determine the clinical significance and cost effectiveness of decreased biofilm formation and the impact it has on tube occlusion and infection.

The decision for insertion of a short-term tube $v$ s a long-term tube not only depends on patient factors, but also on the risks of complications that occur between the tubes. Although still rare, studies have found that long-term tubes have increased incidences of perforation, cholesteatoma and otorrhea. These findings are most likely due to the fact that these tubes remain in the ear longer, have a greater mass and larger flanges passing through the TM on insertion and extrusion. Long-term tubes however, provide the patient with a prolonged ventilation time. This is beneficial to patients that have difficult ear anatomy, including patients with craniofacial abnormalities that are prone to recurrent ear infections and fluid development and may need repeat insertion of TTs. Ultimately, the physician will need to weigh the benefits of prolonged ventilation with the increased risk of complications from long-term tubes.

Tympanostomy tube insertion remains one of the most performed pediatric procedures in the United States each year. With over 600,000 children undergoing anesthesia for this procedure, it is imperative that the a tube with adequate ventilation, low extrusion rates, tube otorrhea and infection be chosen to minimize repeat trips to the operating room for reinsertion. New technologies now enable us to look with more detail at the effect surface composition and tube material has on TM healing, allowing investigators to create more effective tubes. More clinical trials still need to be performed in order to determine whether or not these changes have any clinical significance with regards to tube function. Ultimately however, the decision for which tube to insert rests with the surgeon and their experience and comfort with that specific TT.

\section{REFERENCES}

1. Vital and health statistics: ambulatory and inpatient procedures in the United States, 1996. Series 13: data from the National Health Care Survey No. 139. US Department of Health and Human Services. Hyattsville, MD, Nov 1998, DHHS Publication No (PHS) 99-1710;13.

2. Derkay CS. Pediatric otolaryngology procedures in the US: 1978-1987. Int J Pediatr Otorhinolaryngol 1993;25:1-12.

3. Cullen KA, Hall MJ, Golosinskiy A. Ambulatory surgery in the United States, 2006. Natl Health Stat Report 2009;(11):1-25.

4. Kogan MD, Overpeck MD, Hoffman HJ, Casselbrant ML. Factors associated with tympanostomy tube insertion among preschool-aged children in the United States. Am J Public Health 2000;90(2):245-250.

5. Centers for disease control and prevention [Internet]. Table 2: Top 5 diagnoses at visits to office-based physicians and hospital outpatient departments by patient age and sex: United States 2008. In: National Ambulatory Health Care Survey 2008. Atlanta, GA: Centers for Disease Control and Prevention; 2008. Available www.cdc.gov/nchs/ahcd/web_tables. htm.

6. Frank M. Praktische anleitung zur Erkenntniss und Behandlung der Ohrenkrankheiten, Enke, Erlangen, 1845. p. 310.

7. Bonnafont JP. Traite the'orique et pratique des maladies de l'oreille, Baillie`re, Paris, 1860. p. 374.

8. Levi DM. Des divers moyens propose's pour maintenir ouverte une perforation chirurgicale de lamembranetympanique. Ann Mal Oreille Larynx 1 1875;349-356.

9. Politzer A. Lehrbuch der Ohrenheilkunde, Enke, II Band, Stuttgart 1882. p. 434.

10. Mudry A. The tympanostomy tube: an ingenious invention of the mid 19th century. Int J Pediatr Otorhinolaryngol 2013 Feb;77(2):153-157.

11. Armstrong BW. A new treatment for chronic secretory otitis media. Arch Otolaryngol 1954;69:653-654.

12. Rosenfeld RM, Isaacson GC. Tympanostomy tube care and consequences. In: Rosenfeld RM, Bluesone CD, editors. Evidence-Based Otitis Media. Hamilton, Ontario: BC Decker Inc 1999;315-336.

13. Karlan MS, Skobel B, Grizzard M, et al. Myringotomy tube materials: bacterial adhesion and infection. Otolaryngol Head Neck Surg 1980;88:783-795.

14. Kay DJ, Nelson M, Rosenfeld RM. Meta-analysis of tympanostomy tube sequelae. Otolaryngol Head Neck Surg 2001;124:374-380.

15. van Baarle PWL, Wentges RT. Extrusion of transtympanic ventilating tubes, relative to the site of insertion. ORL J Otorhinolaryngol Relat Spec 1975;37:35-40.

16. Tami TA, Kennedy KS, Harley E. A clinical evaluation of goldplated tubes for middle ear ventilation. Arch Otolaryngol Head Neck Surg 1987;113:979-980.

17. Shone GR, Griffith IP. Titanium grommets: a trial to assess function and extrusion rates. J Laryngol Otol 1990;104:197-199.

18. Soderberg O, Hellstrom SOM. Effects of different tympanostomy tubes (Teflon and stainless steel) on the tympanic membrane structures. In: Lim DJ, Bluestone CD, Klein JO, 
Nelson JD, editors. Recent advances in otitis media. Proceedings of the Fourth International Symposium. Toronto: BC Decker 1988. p. 280-282.

19. Jang $\mathrm{CH}$, Park $\mathrm{H}$, Cho $\mathrm{YB}$, Choi $\mathrm{CH}$, Park IY. The use of piperacillin-tazobactam coated tympanostomy tubes against ciprofloxacin-resistant pseudomonas biofilm formation: an in vitro study. Int J Pediatr Otorhinolaryngol 2009 Feb;73(2): 295-299.

20. Jang $\mathrm{CH}$, Park $\mathrm{H}, \mathrm{Cho} \mathrm{YB}, \mathrm{Choi} \mathrm{CH}$. Effect of vancomycincoated tympanostomy tubes on methicillin-resistant Staphylococcus aureus biofilm formation: in vitro study. J Laryngol Otol 2010 Jun;124(6):594-598.

21. Kinnari TJ, Salonen EM, Jero J. Durability of the binding inhibition of albumin coating on tympanostomy tubes. Int $\mathrm{J}$ Pediatr Otorhinolaryngol 2003 Feb;67(2):157-164.

22. Kinnari TJ, Jero J. Experimental and clinical experience of albumin coating of tympanostomy tubes. Otolaryngol Head Neck Surg 2005 Oct;133(4):596-600.

23. Kinnari TJ, Rihkanen H, Laine T, Salonen EM, Jero J. Role of albumin coating of tympanostomy tubes: long-term clinical evaluation. Laryngoscope 2007 Dec;117(12):2213-2217.

24. Berry JA, Biedlingmaier JF, Whelan PJ. In vitro resistance to bacterial biofilm formation on coated fluoroplastic tympanostomy tubes. Otolaryngol Head Neck Surg 2000;123: 246-251.

25. Ojano-Dirain CP, Silva RC, Antonelli PJ. Biofilm formation on coated silicone tympanostomy tubes. Int J Pediatr Otorhinolaryngol 2013 Feb;77(2):223-227.

26. Patel NA, Sherman EG, Antonelli PJ. Effect of tympanostomy tube surface on occlusion. Int J Pediatr Otorhinolaryngol 2012 Jul;76(7):960-962.

27. Tatar EC, Unal FO, Tatar I, Celik HH, Gursel B. Investigation of surface changes in different types of ventilation tubes using scanning electron microscopy and correlation of findings with clinical follow-up. Int J Pediatr Otorhinolaryngol 2006 Mar;70(3):411-417.

28. Licameli G, Johnston P, Luz J, Daley J, Kenna M. Phosphorylcholine-coated antibiotic tympanostomy tubes: are post-tube placement complications reduced? Int J Pediatr Otorhinolaryngol 2008 Sep;72(9):1323-1328.

29. Hong P, Smith N, Johnson LB, Corsten G. A randomized double-blind controlled trial of phosphorylcholine-coated tympanostomy tube versus standard tympanostomy tube in children with recurrent acute and chronic otitis media. Laryngoscope 2011 Jan;121(1):214-219.
30. Wang JC, Hamood AN, Saadeh C, Cunningham MJ, Yim MT, Cordero J. Strategies to prevent biofilm-based tympanostomy tube infections. Int J Pediatr Otorhinolaryngol 2014 Sep;78(9): 1433-1438.

31. Chole RA, Hubbell RN. Antimicrobial activity of silastic tympanostomy tubes impregnated with silver oxide. A double-blind randomized multicenter trial. Arch Otolaryngol Head Neck Surg 1995 May;121(5):562-565.

32. Levinson SR, Gill AJ, Teich L. Semipermeable membrane tubes: a prospective study. Otolaryngol Head Neck Surg 1982;90:622-628.

33. Plotkin RP. Middle ear ventilation with the castelli membrane tube. Laryngoscope 1981;7:1173-1175.

34. Weigel MT, Parker MY, Manning M, et al. A prospective randomized study of four commonly used tympanostomy tubes. Laryngoscope 1989;99:252-256.

35. Kalcioglu MT, Cokkeser Y, Kizilay A, Ozturan O. Follow-up of 366 ears after tympanostomy tube insertion: why is it draining? Otolaryngol Head Neck Surg 2003 Apr;128(4): 560-564.

36. Hill F. The triune, a new silicone tympanostomy tube. Otolaryngol Head Neck Surg 2006 Mar;134(3):524-525.

37. Handler SD, Miller L, Potsic WP, Wetmore RF, Marsh RR. A prospective study of titanium ventilation tubes. Int J Pediatr Otorhinolaryngol 1988;16:55-60.

38. Sherman EG, Antonelli PJ, Tran-Son-Tay R. Development of a calcium alginate tympanostomy tube. Laryngoscope 2010 Dec;120(12):2473-2477.

39. Jeon EJ, Park YS, Lee SK, Chang KH, Park SY, Park KH, Lee $\mathrm{DH}$. Factors of the blockage of ventilation tubes in the immediate postoperative period. Eur Arch Otorhinolaryngol 2007 Dec;264(12):1393-1397.

40. Burke EL, Walvekar RR, Lin J, Hagan J, Kluka EA. Common agents used to unblock blood clots within tympanostomy tubes: an ex vivo study and review of literature. Int J Pediatr Otorhinolaryngol 2009 Dec;73(12):1725-1728.

41. Mehta AJ, Stevens GR, Antonelli PJ. Opening plugged tympanostomy tubes: effect of inner diameter and shaft length. Otolaryngol Head Neck Surg 2005 Feb;132(2):322-326.

42. Tsao BA, Stevens GR, Antonelli PJ. Opening plugged tympanostomy tubes: effect of tube composition. Otolaryngol Head Neck Surg 2003 Jun;128(6):870-874. 